\title{
Energy Dependence of Ge Amorphization by Ne, Ar or Kr Ion Irradiation*
}

\author{
R. C. Birtcher \\ Materials Science Division \\ Argonne National Laboratory \\ Argonne, IL 60439 \\ ANL/MSD/PP- 84667
}

$\$ 1306$

4

October 1994

\begin{abstract}
The submitted manuscript has been authored by a contractor of the U.S. Government under contract No. W-31-109-ENG-38. Accordingly, the U.S. Government retains a nonexclusive, royalty-free license to putilsh or reproduce the published form of this contribution, or allow others to do so, for U.S. Government purposes
\end{abstract}

\section{DISCLAIMER}

This report was prepared as an account of work sponsored by an agency of the United States Government. Neither the United States Government nor any agency thereof, nor any of their employees, makes any warranty, express or implied, or assumes any legal liability or responsibility for the accuracy, completeness, or usefulness of any information, apparatus, product, or process disclosed, or represents that its use would not infringe privately owned rights. Reference herein to any specific commercial product, process, or service by trade name, trademark, manufacturer, or otherwise does not necessarily constitute or imply its endorsement, recommendation, or favoring by the United States Government or any agency thereof. The views and opinions of authors expressed herein do not necessarily state or reflect those of the United States Government or any agency thereof.

*Work supported by the U. S. Department of Energy, BES-Materials Sciences, under Contract W-31-109-Eng-38. 


\section{DISCLAMMER}

Portions of this document may be illegible in electronic image products. Images are produced from the best available original document. 


\title{
Energy Dependence of Ge Amorphization by Ne, Ar or Kr Ion Irradiation
}

\author{
R. C. Birtcher \\ Materials Science Division, Argonne National Laboratory, Argonne, IL 60439
}

Ge has been irradiated at room temperature with $\mathrm{Ne}, \mathrm{Ar}$ or $\mathrm{Kr}$ ions of different energies, and the doses required for complete amorphization determined by in situ transmission electron microscopy and electron diffraction. Onset of amorphization was detected after the lowest ion doses reflecting amorphization by individual ions. The ion dose required for complete amorphization increased nearly linearly with ion energy over the range $0.5 \mathrm{MeV}$ to $3.5 \mathrm{MeV}$ for all ions. Amorphization cross sections have been determined for all ions and energies used. The displacements per atom required for complete amorphization decreased with increasing ion energy or ion mass. This decrease is due to a decrease in radiation annealing of amorphous volumes as a result of a decrease in the fraction of low energy transfers to Ge atoms. Increasing the relative fraction low energy transfers to Ge atoms by simultaneous $1 \mathrm{MeV}$ electron irradiation increased the $\mathrm{Kr}$ ion dose required for complete amorphization by as much as a factor of 2.5. The effect is believed to be due to an increase in the fraction of freely migrating defects produced by low energy transfers to Ge atoms. 
Among the effects produced by the interaction of energetic ions with matter, disruption of a crystalline lattice to the point of amorphization is among the most complex and least understood. The amorphous state is metastable, existing over a limited range of temperature, and its formation requires external energy input. This can be achieved by several techniques one of which is radiation damage.

Investigations of irradiation induced amorphization have been performed on many intermetallic alloy systems, and models to understand amorphization have been developed based on elastic shear instabilities and the energy stored in defects and chemical disorder [1]. By their very nature, radiation effects in alloy systems involve inseparable contributions from both chemical disordering as well as defect production. Only a few elemental systems such as $\mathrm{Si}$ and $\mathrm{Ge}$ are known to amorphize. Ge is amorphized during ion irradiation by single cascade events [2]. Above room temperature, the ion dose required for complete amorphization of $\mathrm{Ge}$ increases with increasing temperature, and an upper temperature limit for Ge amorphization by $1.5 \mathrm{MeV} \mathrm{Kr}$ ions was determined to be approximately $300^{\circ} \mathrm{C}$ [3]. Such a dependence is similar to that found for amorphization of other materials and is believed to be due to competition between amorphization and thermally driven defect recovery [1].

In addition to temperature and ion dose dependencies, Ge amorphization was found to be sensitive to the specimen thickness [3]. At $200^{\circ} \mathrm{C}$ during in situ electron microscopy observation during ion irradiation, the thinnest part of a specimen near the edge of the initial perforation in the specimen was amorphized, but at the same time, thicker but still fully irradiated regions remained crystalline while radiation-induced dislocation loops formed. Still thicker regions remained crystalline and contained a lower density of larger loops. This thickness dependence is believed to be due to a lowering of the thermally migrating defect concentration by annihilation at the specimen 
surfaces resulting in reduced radiation annealing of amorphized volumes in thinner regions and thus lower amorphization doses.

Brilluoin scattering has been used to determine the volume fraction of amorphous Ge during 3.5 $\mathrm{MeV} \mathrm{Kr}$ ion irradiation at room temperature [4]. The absolute value of the cross section for amorphization was determined to be 4.5 $\mathrm{nm}^{2}$. When in situ electron diffraction was used to determine the complete amorphization dose for this irradiation, the volume fraction of crystal material remaining after amorphization was $1 \cdot 10^{-4}$. In this work the ion dose required for complete amorphization at room temperature of thin Ge foils has been studied as a function of both ion mass and energy using in situ electron diffraction. The spectrum of ion masses and energies used result in energy transfers to the Ge atoms extending over two orders of magnitudes. The energy dependence of the cross section for complete amorphization was extracted using the value determined for $3.5 \mathrm{MeV} \mathrm{Kr}$ ions.

\section{EXPERIMENTAL}

In-situ irradiations were performed at the HVEM-Tandem Accelerator Facility [5] at Argonne National Laboratory. The facility consists of a modified Kratos/AEI EM7 high voltage electron microscope (HVEM) and a 2 MV tandem National Electrostatics ion accelerator. Ion energies above $1.5 \mathrm{MeV}$ were achieved through the use of double charged ions. Specimens were formed from polycrystalline Ge (99.9999 at. \% pure) with grain size $>5 \mu \mathrm{m}$. TEM discs were core drilled and jet-polished to perforation [6]. Typical specimen thicknesses in the observed areas were determined by electron energy loss techniques in a Philips 420 electron microscope to be about $50 \mathrm{~nm}$. The only defects observed in the as-polished samples were isolated dislocations and grain boundaries. All irradiations were performed at room temperature, and a separate specimen was used for each ion energy. The highest temperature recorded by a thermocouple on the specimen holder during ion irradiation was less than $50^{\circ} \mathrm{C}$. The electron 
energy in the HVEM was maintained at $300 \mathrm{kV}$ which is below the displacement threshold of Ge for electron irradiation [7].

The ion dose required for complete amorphization at room temperature was determined for $\mathrm{Ne}, \mathrm{Ar}$ and $\mathrm{Kr}$ ions with energies between 0.15 and $3.5 \mathrm{MeV}$. Dose rates of 3 to $4 \cdot 10^{-3}$ ions $/ \mathrm{nm}^{2} \mathrm{sec}$ were used for all irradiations. In order to avoid an increase in the amorphization dose because of synergistic effects from simultaneous electron irradiation [8,9], the electron beam was turned off during ion irradiations. Periodically during each irradiation, the ion beam was interrupted and electron diffraction patterns were recorded. In situ observations allowed changes in one area to be monitored during an entire irradiation. Amorphization was discernable by diffuse rings in the electron diffraction pattern.

Ge is amorphized by individual ions [2], so that a diffuse ring was detectable in the diffraction pattern after any low ion dose. Detection of the onset of amorphization was limited only by detectability of viewing a weak diffuse ring in the presence of intense diffraction spots. For example during $1.5 \mathrm{MeV} \mathrm{Kr}$ ion irradiation, a diffuse ring was observed in the diffraction pattern after doses as low as $0.03 \mathrm{Kr} / \mathrm{nm}^{2}$ or an estimated 0.002 displacements per atom, dpa. Similarly the ability to determine the complete amorphization dose was limited by the ability to detect the disappearance of all Bragg diffraction spots from a diffraction pattern containing several intense diffuse rings. For this reason, the amorphization dose was determined by examination of electron diffraction micrographs and not from the viewing screen in the HVEM. The complete amorphization dose was determined from the first electron diffraction micrograph that did not contain discernable Bragg diffraction spots from crystalline Ge. Because discreet observations were made, the complete amorphization doses are uncertain by an irradiation step or approximately $5 \%$. These determinations are some what subjective, but the same procedure was used in all cases and the results are internally consistent. The volume fraction of crystalline material remaining at 
the complete amorphization dose determined by this technique was $1 \cdot 10^{-4}$ for 3.5 Mev $\mathrm{Kr}$ ions [4].

During two $\mathrm{Kr}$ ion irradiations, additional point defect damage was produced by simultaneous irradiation with a $1 \mathrm{MeV}$ electron beam focused into a Gaussian profile having a full width at half maximum of approximately $2 \mu \mathrm{m}$. This focused beam of approximately $1 \cdot 10^{5} \mathrm{e}^{-/ \mathrm{nm}^{2}}$ sec produced an average of $0.4 \cdot 10^{-3} \mathrm{dpa} / \mathrm{sec}$ at its center. At the same time the entire specimen was uniformly irradiated with a $1 \mathrm{MeV} \mathrm{Kr}$ ion beam that produced $1 \cdot 10^{-3} \mathrm{dpa} / \mathrm{sec}$ or a $2 \mathrm{MeV} \mathrm{Kr}$ ion beam that produced $0.8 \cdot 10^{-3} \mathrm{dpa} / \mathrm{sec}$.

TRIM [10] calculations were performed for all ions and energies for a specimen thickness of $50 \mathrm{~nm}$ using $15 \mathrm{eV}$ as the Ge displacement energy [7]. A primary experimental uncertainty in determining the energy dependence of amorphization arises from ion energy loss and stopping which lead to variation of damage production through the specimen thickness. These effects are greatest for heavier ions at lower energies. Trim calculations indicate that a $0.5 \mathrm{MeV} \mathrm{Kr}$ ion lost on average about $25 \%$ of its initial energy, and the retained fraction of $\mathrm{Kr}$ was less than $2 \%$ resulting in an average implanted $\mathrm{Kr}$ concentration of less than 9 appm in the electron transparent region of the specimen at the complete amorphization dose of $0.8 \mathrm{Kr} / \mathrm{nm}^{2}$. At higher energies, both $\mathrm{Kr}$ retention and fractional energy loss in the electron transparent areas of the Ge specimen were significantly lower. Calculations show that less than $2 \%$ of the ions were retained for $\mathrm{Ar}$ ions with energies above $0.25 \mathrm{MeV}$ or $\mathrm{Ne}$ ions with energy above above 0.2 $\mathrm{MeV}$. Less than a monolayer of Ge was removed by sputtering after irradiation by any ion to its complete amorphization dose.

\section{RESULTS and DISCUSSION}

\section{A: Amorphization Doses}

Ion doses required for complete amorphization of thin Ge specimens at room temperature were determined by in situ electron diffraction. Examples of electron 
diffraction patterns taken during interruptions of a $1.5 \mathrm{MeV}$ Ne ion irradiation are shown in Figure 1. A diffuse ring indicating partial amorphization was observed in the electron diffraction pattern after doses as low as $0.002 \mathrm{dpa}$. This is only a practical limit and not an indication of a threshold dose. In Fig. 1B, weak rings from amorphous material are visible along with remaining Bragg spots from the residual crystalline volume fraction. During irradiation, diffraction intensity shifts from the Bragg spots to the diffuse rings. The sequence of diffraction patterns in Fig. 1 are typical of those used in this experiment, and similar sequences of images were made during $\mathrm{Kr}, \mathrm{Ne}$ and $\mathrm{Ar}$ ion irradiations at several energies.

The energy dependences of the complete amorphization doses determined for $\mathrm{Ne}, \mathrm{Ar}$ and $\mathrm{Kr}$ ion irradiations are shown in Figure 2. The ion dose required for complete amorphization at a given energy is lower for a heavier ion. This is a consequence of increasing collision cross section and energy deposition with increasing ion mass. For each ions, the ion dose required for complete amorphization increases with increasing ion energy. This is a consequence of a decreasing cross section for nuclear collisions with increasing ion energy and a decreasing efficiency to produce damage with increasing energy transferred to the lattice atoms [11]. In crystalline materials, the damage production efficiency is a strong function of the primary recoil energy energy decreasing from $100 \%$ for single defect production by low energy events to about $30 \%$ for cascades with an average energy of $20 \mathrm{keV}$ [11]. Molecular dynamic simulations indicate that this is due to defect recovery within the cascade. Similar measurements or calculation have not been made for production of amorphous volumes, and the dependence of the size of the amorphous volume on the energy of the damage event is not known.

Linear least squared fits were made to the curves in Fig. 2. With the exception of $\mathrm{Ne}$ and $\mathrm{Ar}$ ions with energies less than $0.5 \mathrm{MeV}$, the data for all ions can be described by an empirical equation of the form 


$$
\left.\mathrm{D}^{\text {Ion }}=\mathrm{D}_{0} \operatorname{Ion}_{*[1}+\mathrm{S}_{\mathrm{d}} * \mathrm{E}^{\mathrm{ion}}\right]
$$

where $D^{i o n}$ is ion dose for complete amorphization, $D_{0}$ Ion is the ion dose required at zero ion energy, $E^{i o n}$ is the ion energy in $\mathrm{MeV}$ and $\mathrm{S}_{\mathrm{d}}$ is given by $\mathrm{S}^{I} \mathrm{n}_{/} / \mathrm{D}_{0}$ Ion where $S^{T}$ is the rate of increase of the complete amorphization doses with ion energy. The values of these parameters are listed in Table I. The relationship of $\mathrm{D}_{0}$ Ion to ion mass in the range of $\mathrm{Ne}$ to $\mathrm{Kr}$ can be described by a power law with an exponent of -2.5. These parameters provide a simple empirical method to estimate the complete amorphization dose for Ge at room temperature. The values of $S_{d}$, given in Table $I$, are about $0.75 / \mathrm{MeV}$ independent of ion type. This suggests thrt $S_{d}$ is a materials property that is to first order proportional to the number of defects required to amorphize a unit volume divided by the cross section to produce damage.

\section{B: Amorphization Cross Section}

The complete amorphization doses can be converted to amorphization cross sections. The dose dependence of the amorphous volume fraction during $3.5 \mathrm{MeV}$ $\mathrm{Kr}$ irradiation at room temperature has been determined by Brilluoin scattering [4]. The volume fraction of crystalline material decreased as $f_{x}=e^{-\sigma \phi}$, where $\varphi$ is the ion dose and $\sigma$ is the cross section for amorphization for a given ion of a given energy. Based on the value of $4.5 \pm 0.3 \mathrm{~nm}^{2}$ for $3.5 \mathrm{MeV} \mathrm{Kr}$ ions, the fraction of crystalline material remaining after TEM observation of the disappearance of all diffraction spots at the "complete amorphization" dose was $1 \times 10^{-4}(\sigma \varphi=9.2)$. Assuming that this volume faction is the same for all in situ TEM observations in this work, the amorphization cross section was calculated for all irradiations and is shown in Figure 4 as a function of ion energy.

As expected, the amorphization cross section decreases with increasing ion energy or decreasing ion mass. The experimental values of the amorphization cross section can be compared to full cascade TRIM calculations of the damage produced by each irradiation, and the results are shown as solid lines in Figure 4. 
Since the fraction of damage converted into amorphous volume is not known, the TRIM results have been normalized to the values of the damage produced and the amorphization cross section for $3.5 \mathrm{MeV} \mathrm{Kr}$ ions. The TRIM calculations adequately describe the results of the $\mathrm{Kr}$ and Ar irradiations except when ion stopping affects the experimental results. However, the TRIM calculations are $30 \%$ higher than the experimental data for the Ne irradiations. This is due to greater radiation induced annealing during irradiation with lighter ions and indicates a change in the production of amorphous volumes during irradiation. This is discussed in the next sections.

\section{C: Amorphization dpa}

The ion doses required for complete amorphization can be related to more physical terms by their conversion to displacements per atom, dpa. TRIM 91 full cascade calculations were made, and the average amount of damage produced in a $50 \mathrm{~nm}$ thick Ge layer was determined for each irradiation. Because the calculations are sensitive to cascade termination at both surfaces, accurate thickness measurement of each specimen area monitored would be required for precise determination of the number of atomic displacements required for amorphization. Since this measurement could not be performed on all specimens, a thickness of $50 \mathrm{~nm}$ was used for all calculations. It must be remarked that there are serious limitations to TRIM calculations. Although TRIM does a good job of describing overall features of ion range and energy loss, it contains several approximations that prohibit it from completely describing defect interactions and recombination within high density displacement events and the interaction between displacement events. TRIM calculations can not account for the decrease in the efficiency to produce damage with increasing cascade energy.

The amorphization doses for all irradiations expressed in terms of displacements per atom are shown in Figure 3 as functions of ion energy. The lines in Figure 3 are linear fits, and values of the intercepts, $D_{0} d p a$, and 
slopes, $\mathrm{S}^{\mathrm{dpa}}$, for these fits are given in Table I. The number of displacements required for complete amorphization decreases with increasing ion mass and ion energy. The dependence of complete amorphization on ion energy is largest for lighter ions such as $\mathrm{Ne}$ and least for heavier ions such as $\mathrm{Kr}$. The effectiveness of an irradiation to amorphize Ge increases with ion mass and energy. Irradiations that generate dense cascades are more effective in amorphizing $\mathrm{Ge}$ and rather insensitive to ion energy while irradiations dominated by low energy transfers are less effective and very sensitive to ion energy. This trend is counter to the dependence of damage production at low temperatures in metals where more energetic cãscades are less effective in producing damage when defects are immobile. The difference in behavior is due to annealing of preexisting amorphous volumes as a result of a decrease in the fraction of low energy transfers to Ge atoms. Low energy transfers produce freely migrating defects. The fraction of damage produced as freely migrating defects decreases with increasing ion energy and ion mass, and thus heavier ions exhibit less of this effect.

D: Impact of Low Energy Displacements and Freely Migrating Defects

Variation of the amount of damage required for amorphization with ion mass can be explained if the stability of an amorphous volume is affected by the energy distribution of atomic recoils produced by the different irradiations. As examples of such effects, the ion doses for amorphization of $\mathrm{Si}$ or $\mathrm{CuTi}$ are known to be affected by the additional defects from low energy transfers created by simultaneous electron irradiation $[8,9]$. Direct observations have shown that room temperature electron irradiation at energies below the displacement threshold result in crystallization of amorphous volumes in ion irradiated $\mathrm{Ge}, \mathrm{Si}$, GaAs and GaP [12].

To investigate the effect on complete amorphization dose, Ge was irradiated with a focused $1 \mathrm{MeV}$ electron beam during $\mathrm{Kr}$ ion irradiation. In the area 
irradiated with both $1 \mathrm{MeV}$ electrons and with $2 \mathrm{MeV} \mathrm{Kr}$ ions, the ion dose required for complete amorphization was increased by more than a factor of 2.5 over the value found in nonelectron irradiated areas even though the maximum Ge displacement rate from the electron irradiation was about $50 \%$ of that produced by the $\mathrm{Kr}$ irradiation. The fractional increase was about $20 \%$ for simultaneous $1 \mathrm{MeV}$ electron and $1 \mathrm{MeV} \mathrm{Kr}$ ion irradiations.

A $1 \mathrm{MeV}$ electron irradiation transfers up to $60 \mathrm{eV}$ to a Ge atom resulting in one or two atomic displacements. Such an electron irradiation does not amorphize Ge at room temperature. Electron irradiation suppression of ion beam amorphization was determined as a function of temperature for $\mathrm{Si}$ [8] and $\mathrm{CuTi}$ [9]. The effect occurs when defects are mobile and electron irradiation alone is unable to amorphize the material. When defects are immobile at low temperature, the electron damage adds to the ion damage lowering the ion dose required for complete amorphization. Suppression of amorphization can be attributed to either annealing of amorphous zones directly by electron collisions at the interface between an amorphous volume and the surrounding crystalline material or annealing by freely-migrating defects produced by low energy displacement events in the crystalline regions. The temperature dependence suggest that the latter is responsible for the effect.

The sensitivity of the $\mathrm{Kr}$ dose required for complete amorphization to simultaneous electron irradiation indicates that the dependence of the complete amorphization on ion mass and energy is due at least in part to differences in the fraction of low energy atomic recoils and to variation of the production of freely migrating defects. In crystalline materials, the fraction of freely migrating defects decreases strongly with increasing ion mass and energy [13]. For a particular ion mass, low energy transfers and freely migrating defect production is more dominate at lower ion energies. Dense cascades, such as those produced by a $\mathrm{Kr}$ ion irradiation, approach a limiting case in which the fraction of freely migrating defects is only a few percent. Light ions such as Ne have a larger 
fraction of low energy displacement events than a heavy ion such as $\mathrm{Kr}$. The low energy damage component of a $\mathrm{Ne}$ irradiation acts like an electron irradiation and increases the number of atomic displacements required for complete amorphization above that found for a $\mathrm{Kr}$ irradiation.

\section{CONCLUSIONS}

The ion doses required to amorphize Ge at room temperature by ions of different masses and energies have been determined and expressed as cross sections for amorphization and in terms of displacements per atom. The ion dose required for complete amorphization increases with increasing ion energy and decreases with increasing ion mass. The $\mathrm{Kr}$ ion dose required for amorphization is increased by simultaneous electron irradiation. The number of displacements per atom required for complete amorphization decreases with increasing ion energy and ion mass. Irradiations that are dominated by low energy displacement events require the highest number of displacements per atom. This is attributed to recovery of amorphous zones during irradiation by freely migrating defects.

\section{ACKNOWLEDGEMENTS}

The author would like to thank B. J. Kestel for sample preparation, the HVEM-Tandem Facility staff for their assistance during ion irradiation, and P. R. Okamoto and L. E. Rehn for helpful discussions. This work has been supported by the U.S. Department of Energy, BES-Materials Sciences, under Contract W-31-109-Eng-38. 
TABLE I

Amorphization Parameters for Ge at Room Temperature

\begin{tabular}{|c||c|c|c||c|c|}
\hline \multirow{3}{*}{ Ion } & $\mathrm{D}_{0}$ Ion & $\mathrm{S}^{\text {Ion }}$ & $\mathrm{S}_{\mathrm{d}}$ & $\mathrm{D}_{0} \mathrm{dpa}$ & $\mathrm{S}^{\mathrm{dpa}}$ \\
\cline { 2 - 6 } & $\mathrm{ions} / \mathrm{nm}^{2}$ & $\mathrm{ions} / \mathrm{nm}^{2} / \mathrm{MeV}$ & $1 / \mathrm{MeV}$ & $\mathrm{dpa}$ & $\mathrm{dpa} / \mathrm{MeV}$ \\
\hline $\mathrm{Ne}$ & 17.8 & 13.3 & 0.747 & .55 & -.048 \\
\hline \multirow{2}{*}{$\mathrm{Ar}$} & 2.58 & 1.98 & 0.767 & .40 & -.031 \\
\hline $\mathrm{Kr}$ & .545 & .411 & 0.754 & .32 & -.005 \\
\hline
\end{tabular}


1 Okamoto and Meshii in Science of Advanced Materials, ed. H. Wiedersich and M. Meshii (American Society for Metals, Metal Park, OH, 1990) p33.

2 L. W. Howe and M. H. Rainville, Nucl. Inst. and Meth. B19/20, 61, (1987).

3 L. M. Wang and R. C. Birtcher, Phil. Mag. A 64, 1209, (1991).

4 R. C. Birtcher, M. H. Grimsditch and L. E. McNeil, Phy. Rev. B1, 50, 8990, (1994).

5 A. Taylor, C. W. Allen, and E. A. Ryan, Nucl. Instrum. Methods B 24/25, 598, (1987).

6 B. J. Kestel, Ultramicroscopy 9, 379 (1982).

7 W. L. Brown and W. M. Augustyniak, J App, Phys. 30, 1300 (1959).

8 D. N. Seidman, R. S. Averback, P. R. Okamoto and A. C. Baily, Phys. Rev. Letters, 59, 900 (1987).

9 J. Koike, P. R. Okamoto, L. E. Rehn and M. Meshii, in Beam-Solid Interactions and Transient Processes, edited by L. E. Rehn, J. Greene and F. A. Smidt (Mater. Res. Soc. Proc. 128, Boston, Ma. 1989) pp. 339.

10 J. J. F. Ziegler, J. P. Biersack and U. Littlemark, 1985, The Stopping Range of Ions in Solids, Peramon Press, New York.

11 R. S. Averback, R. Benedek and K. L. Merkle, Phys. Rev. B18, 4156 (1978).

12 I. Jencic, M. W. Bench, I. M. Robertson and M. A. Kirk, submitted to Phil Mag.

13 L. E. Rehn and R. C. Birtcher, J. Nucl Mater. 205, 31, (1993). 


\section{Figures}

1 Electron diffraction patterns from Ge during 1.5 MeV Ne irradiation at room temperature; A: before ion irradiation, B: after partial amorphization and $\mathrm{C}$ : after complete amorphization.

$2 \mathrm{Ne}, \mathrm{Ar}$ and $\mathrm{Kr}$ ion doses required for complete amorphization of Ge at room temperature as a function of ion energy.

3 Amorphization cross section as a function of $\mathrm{Ne}, \mathrm{Ar}$ and $\mathrm{Kr}$ ion energy. The line are power-law fits to TRIM calculations normalized to the value for $3.5 \mathrm{MeV} \mathrm{Kr}$ ions.

4 Displacements per atom required for complete amorphization of GE at room temperature by $\mathrm{Ne} \mathrm{Ar}$ and $\mathrm{Kr}$ ions as a function of ion energy. 

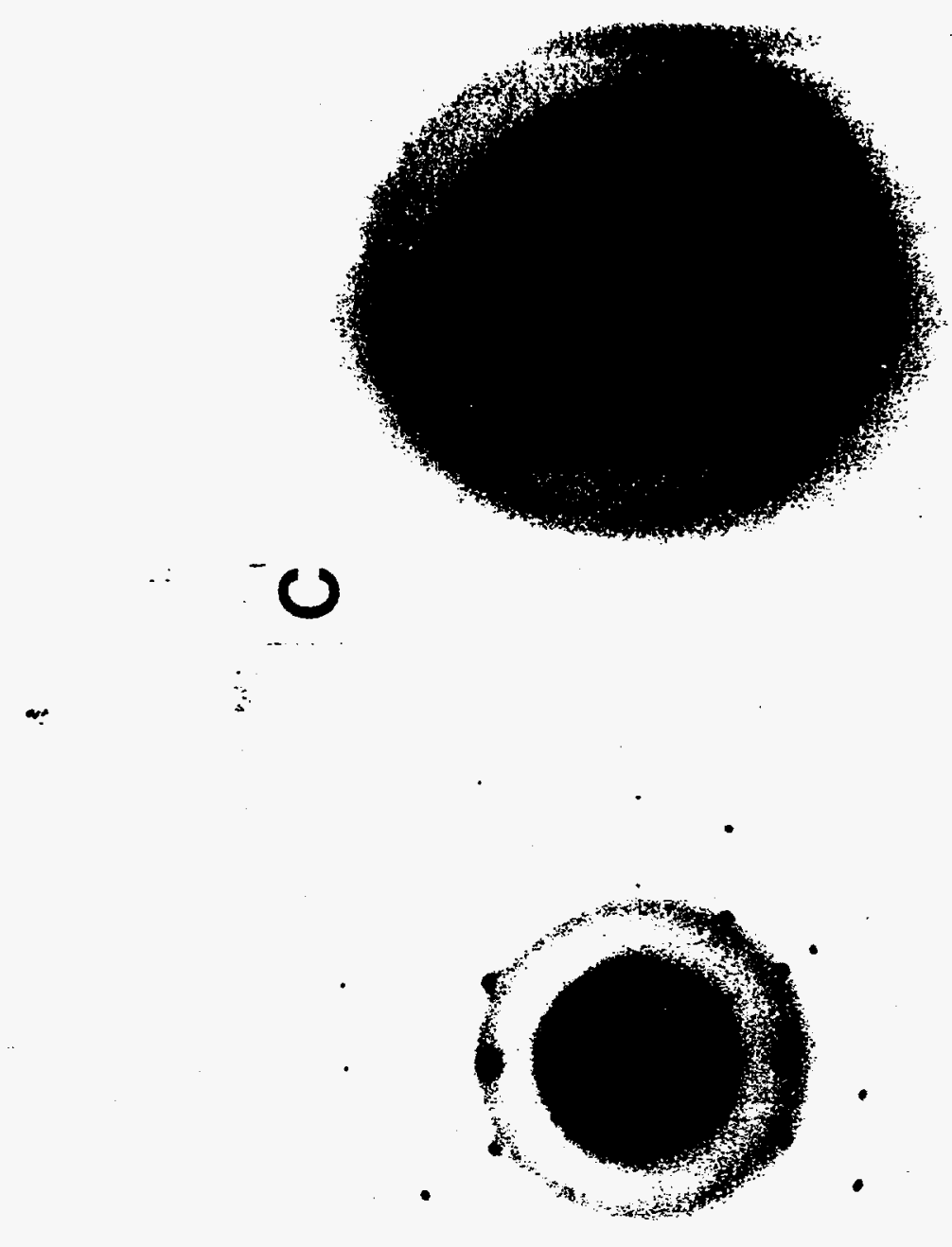

m

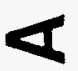

$\overline{F I G} \cdot 1$ 

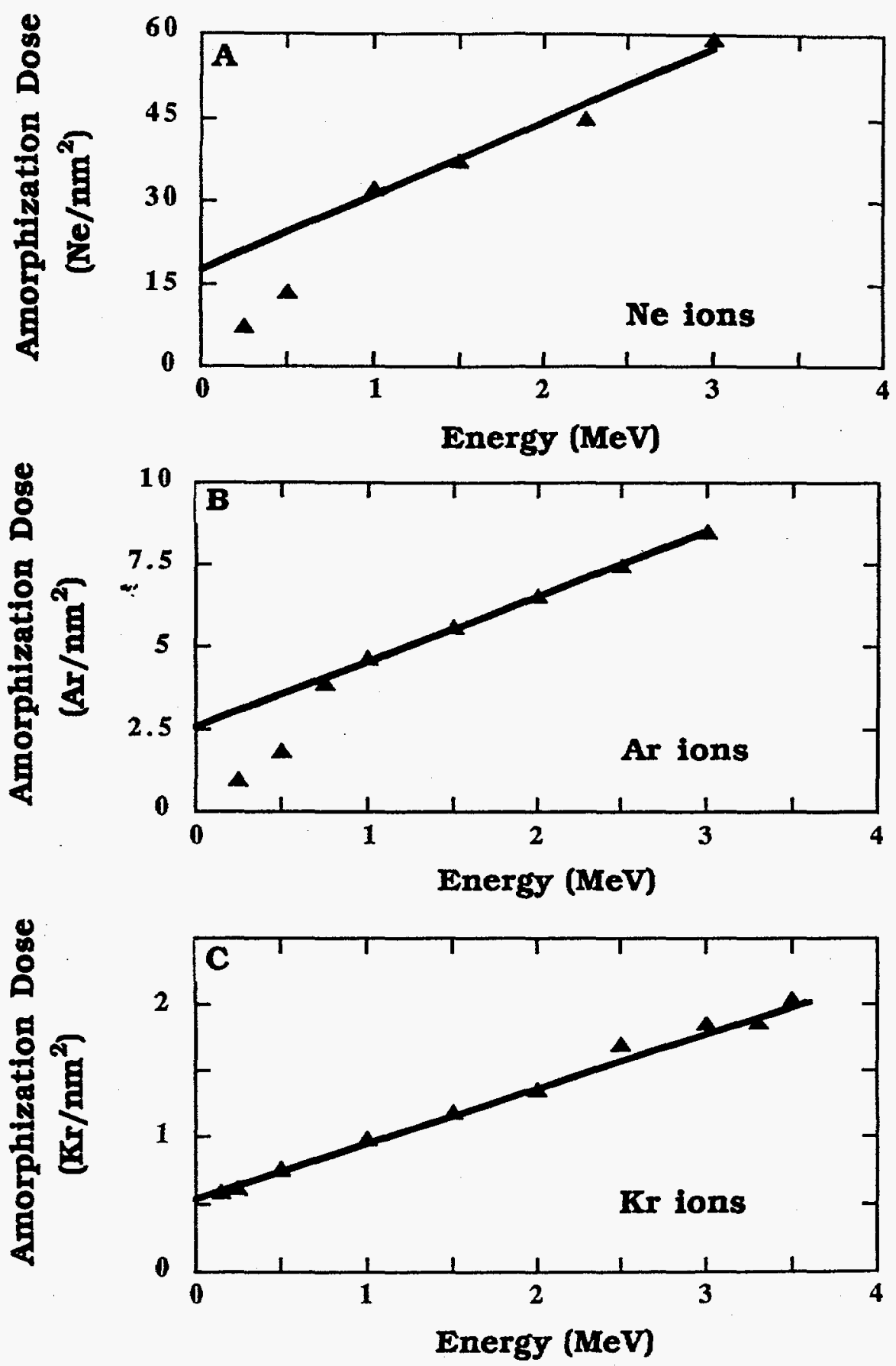

Figure 2. Ions doses required to completely amorphize $\mathrm{Ge}$ at room temperature as a function of ion energy. 


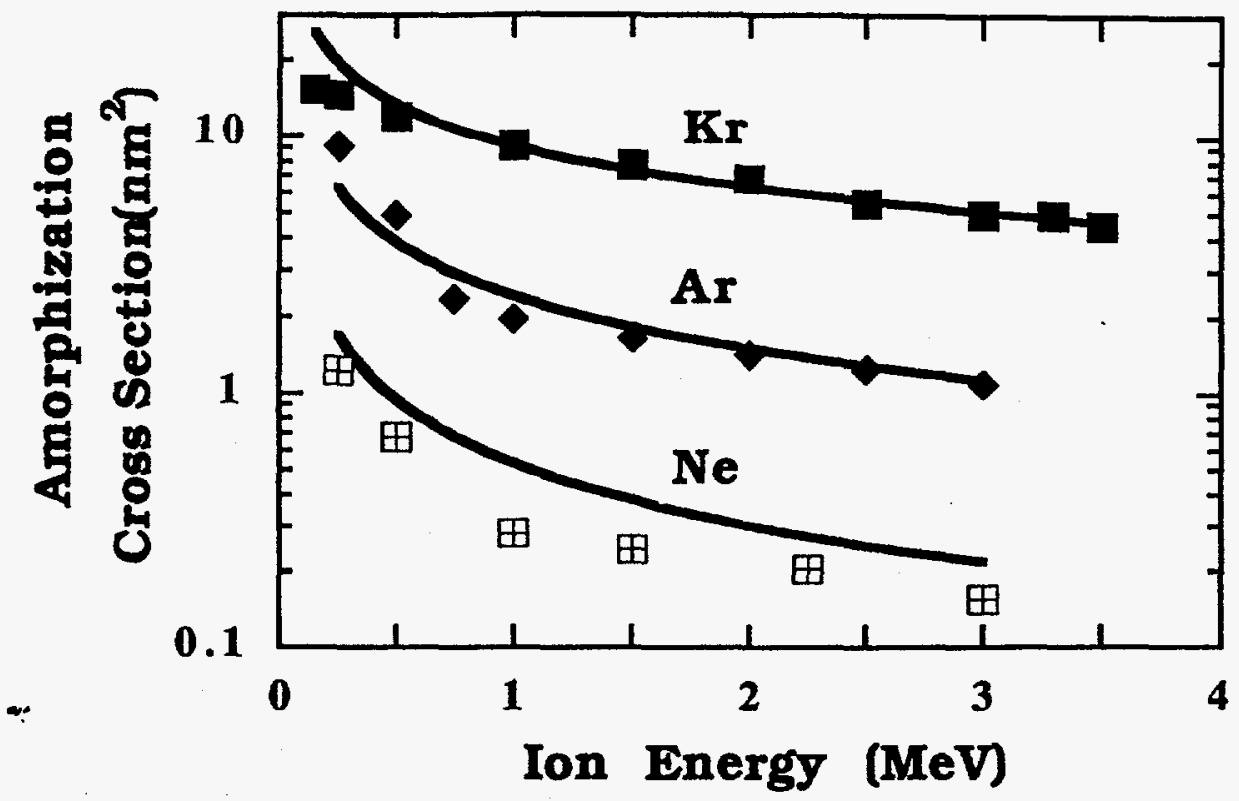

Figure 3. Amorphization cross section as a function of $\mathrm{Ne}, \mathrm{Ar}$ and $\mathrm{Kr}$ ion energy. The line are fits to TRIM calculations normalized to the cross section determined for $3.5 \mathrm{MeV} \mathrm{Kr}$ ions. 


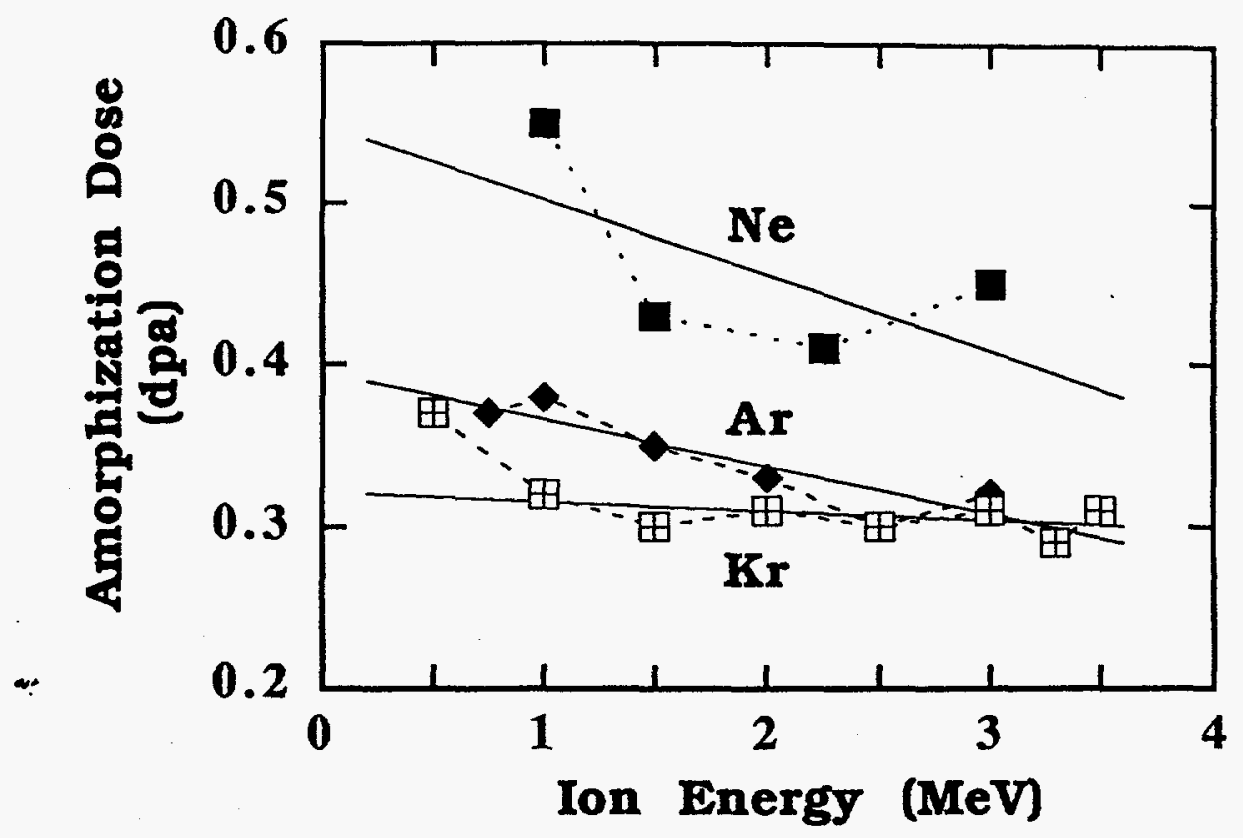

Figure 4. Displacements per atom required for complete amorphization of GE at room temperature by $\mathrm{Ne}$ (solid squares), $\mathrm{Ar}$ (diamonds) and $\mathrm{Kr}$ (open squares) ions as a function of ion energy. 